$\xi=\mathrm{\alpha}$

\title{
The political leadership and corporate governance: an analysis of leadership theories and its influence
}

\author{
Manzoor Ali ${ }^{1 *}$, Lv Tao $^{1}$, Aftab A. Shaikh ${ }^{2}$, Muhammad Sajid ${ }^{1}$ \\ ${ }^{1}$ China University of Mining and Technology, CUMT \\ ${ }^{2}$ Global College of Engineering and Technology, Muscat, Oman \\ *Corresponding authorE-mail: aftabshaikhs@gmail.com
}

\begin{abstract}
The Leaders and their leadership style possess strong influence on corporate sector and its overall working affairs. Effective political leadership is a benchmark for successful corporations as they follow the best strategies from political setup and move towards productivity and efficiency. This paper, therefore, highlights the importance of successful leadership theories and practices, which may follow by the corporate sector for better results. This study explores the influence of political leadership on corporate governance as a corporate sector has to remain under the policy and rule dominancy of the state, hence, this paper elaborates the research questions comprising of 20 items in order to know the influence of political leadership and to analyze the leadership theories and practices in Pakistan.

This paper is quantitative in nature, and close ended questionnaire was used to collect the data from 100 samples comprising of government and private-sector employees working in Pakistan. The statistical tool's factor analysis and correlation are used, and according to the results by factor analysis, 5 components were retained or extracted out of 20 variables. All the variables show high level of correlation with components as cumulative correlation measured by Factor Analysis is .825, which is good in practice. As per results derived from KMO and Bartlett's test, the overall sampling remained .796 that shows a good measurement. In addition to the results, respondents favor that political leadership, and corporate governances are essential ingredients for the organizational development. Majority of respondents were of view that political leadership put strong influence on the affairs of corporate governance.

This paper will help the government and corporate sector to work in collaborative way to achieve their respective goals and run the country and organizations on sound economic track. In continuation, this study also helps the political governments to revisit their influence and ensure complete agreement and harmony with corporate sector, and thus help the corporate sector in performing its role in sustainable economic development.

The necessity of this study was strongly felt as corporate sector in Pakistan has yet to revise its relations with the sitting political government for effective contribution to gross national production (GDP). The performance of corporate sector in terms of productivity and Corporate Social Responsibility (CSR) is not satisfactory at all in Pakistan, but working collaboratively and delegating powers to down level can really help both political and corporate sector to achieve their pre-specified objectives.
\end{abstract}

Keywords: Political Leadership; Corporate Governance; Political Influence; Leadership Theories \& Corporate Sector.

\section{Introduction}

\subsection{Background}

Leaders always have credit to influence their followers in positive manner, whether in political or institutional setup. Talking about sustainable economy of any country, leaders have strong vision and strategies to work with their followers to achieve economic goals. The reflection of successful and effective political leadership may be positive on institutional and corporate sector as vision, goals and objectives are being specified by political leadership creating a way into the institutions to exhibit better corporate governance and achieve their organizational goals. Different authors and scholars have identified the influence of political leadership on corporate governance as Gill [1] said that function of leadership is situational as well as contingency, as leader possess dynamic capabilities, therefore, both behavioral and economic perspective is necessary for the successful leadership. Behavioral perspective may lead to motivation and retention of best employees, and economic perspective can lead to country and organiza- tion on the way towards profitability and success. The effective vision of political leadership can create a benchmark for corporations and hence; so many organizations are following the strategies specified by the political leadership. It may be appropriate to discuss here that many successful companies are contributing to economic development throughout the country, but sustainable business policies and collaboration with political leadership can further strengthen their power and success.

Talking about corporate governance, political leadership can create a culture comprising of strong vision and having strength to pursue it, as it unfolds many successful strategies for the corporate world to go with; this is also necessary for corporate sector to go through benchmarking of successful government strategies and works together with different stakeholders. Decentralization also plays very important role to delegate the authority and power to followers as they can work with complete harmony and confidence. According to Gardner W. L., Avolio B. J., Luthans F. et al et al. [2], a successful leader always transfers his powers to his fellows and associates to accomplish their work in better way. In order to build a task and result oriented environment, he suggests that leader must allow his followers to do by their own as this will 
lead the followers to learn and grow continuously. Organizations often follow strategies in the shape of business policies specified by government, which help the corporate sector to achieve their organizational goals and contribute to national economy. However, this could be opposite when political leadership has unclear vision, lack of collaboration with the business world, and ineffective business policies, which can create hurdles for achieving state and organizational goals.

\subsection{Significance of the study}

This study will provide a way to political leadership to revamp business policies as it put strong influence on the corporate sector which is considered as a backbone of any economy. Corporate sector keeps strong base of investment in any state, therefore, it needs sustainability and better policies that can search a way towards economic development and prosperity. As political leadership sitting in government has legitimate power and position, it can announce more feasible business world which can ensure economic prosperity and success.

This study will help government and corporate sector to work in collaborative manner and build better economic and business policies as both are strong stakeholders of the state.

\subsection{Research objectives}

Following are specific objectives of the study;

- To identify and check the influence of political leadership on the corporate sector.

- To identify the relationship between political leadership and corporate governance with respect to business policies formulation.

\subsection{Definitions of terms}

\subsubsection{Leadership}

There have been lot of investigation and study on the term leadership, but still there is not any single comprehensive definition of leadership. According to famous book Yukl's [3] definition, "leadership is as the process of influencing others to understand and agree about what needs to be done and how to do it, and the process of facilitating individuals and collective efforts to accomplish share objectives".

According to him leadership is a term which influence and facilitate the different work groups and also make it sure that group is ready enough to meet the future challenges.

\subsubsection{Theories of leadership}

There are many theories relating to leadership but main theories are elaborated herewith;

The early leadership concepts were mostly based on two important theories called as Trait Theory and Behavioral Theory. Trait theory believes that leaders hold some traits that are different from others rather than situation in which the leader worked. (Boddy \& Paton [4], Ebert and Griffin [5].

In addition to that, some authors have mostly focused on behavioral perspective and according to them trait theory is missing one important element that is behavior of leader with his followers in particular situation. Leadership theories also consist of contingency/ situational theories, charismatic theories, transactional and transformational theories that may be used in different circumstances for better outcomes. This is very important to discuss that most of theories have adopted from early leadership theories.

\subsubsection{Political leadership}

Political leaders with their authority and power of government can distribute resources, power and authority in order to build strong and sustainable relations with their stakeholders. Political leaders are entitled to build strong framework focusing on long term welfare of citizens. A successful political leadership can work with collaboration to charisma and integrity in order to achieve economic development and sustainability. Political leadership is totally different from politician as the term political leadership refers as position in government and working for the welfare of the state and its citizens. Hsin-yi Cohen [6]

\subsubsection{Corporate governance}

Corporate governance is considered as set of strategies, process and relations by which corporations are managing the work through controlled and directed mechanism. The mechanism identify and distribute the responsibilities among different individuals called board of directors, managers, shareholders, creditors, auditors and other employees working in particular organization. In this set up the objectives are specified and work is monitored through social regulatory and market environment.

\section{Literature review}

Leadership is referred as art of inspiring followers through effective motivational tools used by leader in particular circle. Whether in political or corporate setup, leader creates important culture relating to harmony, co-operation and co-ordination. But, it has been observed that lack of leadership qualities have led to political and business crisis worldwide. Keeping in view the current worldwide crisis into consideration, the leadership theories need to be referred and implemented properly for getting best results and overcome crisis. The political leadership vacuum can create a big challenge for the corporate sector to achieve their objectives and run their business towards productivity and efficiency. According to Mustafa, M.R., Ali et al. [7], certain risks are attached with the poor leadership which may cause to poor governance and administrative risks. These risks in long run can damage the objectivity of the organization and put a negative impression on the team works within organizations. Keeping in view the requirements, there is strong need of effective and better political leadership that may introduce new ways for corporate sector to run on profitability and sustainability. In the similar ways Colley, Doyle, Logan \& Stettinius [8] has put emphasis on achievement of organizational goals can only be possible through social leadership. Social and political leadership can ensure economic and managerial sustainability within the country that can encourage corporate sector to follow the successful strategies and ultimately move towards efficiency and sustainability.

Talking about effective governance, the organization should focus on accountability and transparency as this is best expressed by Anuku and Achienu [9] that organizations should ensure quick and quality oriented accountability, transparency and work performance in order to achieve pre-specified objectives of the organizations. The culture of sound transparency, accountability and equity should be created by political government as this can be exactly followed by corporate sector for smooth and effective running of their business. The strategies being specified by government relating to environmental preservation, pollution and safety are always followed by organizations and hence are considered as bench mark for the corporate sector.

According to the Enabunene [10], government ruling method is not confined to governance within its national boundaries and territories but it is complete system of rule of law, structural arrangements, effective decision making process, implementation of policies, and relationship of government with its stakeholders and smooth flow of country affairs. He articulated the need of national system having political and social interconnection of business, public administration and rule of law.

According to Ogundele Alaka and Balogun [11], governance is referred an integrated part of any state or organization where by it exercise its influence and power as ruler over human and material resources. Whether we are talking about political or corporate setup, its main function is to exercise the powers within its juris- 
diction for achieving pre-specified objectives. Therefore, the credit goes to leader for creating healthy and work-oriented environment where all people work with complete motivation and sense of responsibility.

Almost same opinion is submitted by Omozejie [12], he considers governance as an act and method of controlling, directing and measuring the public affairs of a particular country, hence, he puts emphasis that governance is art of managing affairs within particular city, state or country for effective measurement of results. Leadership theories provide best pictures how leaders are different to each other and why some leaders are successful and some are not. Trait theory of leadership emphasis on the natural traits of people living in particular circle however, behavioral theory in contrast is based on behavior of leaders with their followers. Growing up in particular society, majors traits are possess by some people in the terms of self-confidence, integrity, empathy, assertiveness, good decision-making skills, and likability. In opposite setup, leaders are also defined in the terms of behavior which make it different from the trait theory. Behavioral concept is focused on how leaders behave to their followers as some leaders dictate to their followers while some have motivational strategies to get work done from them. These theories can give some ideas how leaders solve the problems of any country, state or organization. Successful political corporate governance can ensure stability for industrial and institutional sector and hence ensure complete achievement of goals and contribution in sustainable economic development.

Democracy is strong factor in leadership theories specified by various authors. Democratic environment can allow the people to submit their views, produce their ideas, take initiatives and work with complete liberty and harmony. The democracy tradition evolves form the political leadership and may be transferred to corporate leadership for producing better results. According to Hofstede [13] leadership theories favor complete democratic view for achieving leadership roles, as anyone can get on the top by understanding the core concept of democracy. Authors have well defined as better governance is necessary for every size of organization which includes responsibility for controlling and measuring all the resources, ensuring effective use of all resources to pursue quality and objective oriented work.

Corporate governance has been issue not concentrated in 80 s and 90 s as importance of the term was widely ignored by the government officials as well as corporate personnel. According to Shailer and Greg [14] corporate governance has been scarcely existed before $90 \mathrm{~s}$ but now its discussed with much more importance as it plays very crucial role for profitability and sustainability of organization, but role of government and its pattern of governance should be excellent as it can reflect its image on the corporate governance. According to author, subject has spawned consultancies, academic degrees, articles, conferences and important publications to transferring related knowledge for political as well as corporate leaders.

Different authors have contributed different theories relating to political and organizational leadership in terms of effective governance, as Andriessen \& Drenth [15] has elaborated the importance of leadership and has provided certain explanations regarding leaders and their influence on followers to achieve organizational objectives and goals. Theories like trait theory, behavior theory, contingency theory, path-goal leadership theory and transactional and transformational theory are presented in order to help the political and corporate leaders to follow the effective ways of governance within any territory, state and country.

Talking about two important approaches either leaders are born or developed, a famous author Kotter [16] holds a view that successful companies normally do not wait for effective leadership to come along but they try to seek out the human resource that ensure leadership potential and having strong vision and interpersonal skills to motivate their followers and run the business on financially sound basis. This idea is also helpful for political leadership when general public do not see the leaders with natural leadership traits then they should develop and train the people and transfer leadership qualities as that can run the country with effective governance rules and policies. In the same manner, leadership focuses on relationship between leader and his followers within political and organizational context. According to the opinion of Rost [17], that leadership includes power and value-laden relationship between leaders and followers who want real actual change exhibits their mutual objectives and goals.

Ethical consideration is a crucial factor in leadership practices as according to Rubin, Dierdorff and Brown [18] who have conducted experiment comprising of 96 managers and results revealed that ethical leaders having more rating by their supervisor and found suitable for most higher management positions. The people who display less ethical behavior were rarely promoted when compared to ethical leaders who were often promoted for higher management positions. This shows that ethical leaders whether may be in political or corporate setup may find best results while following the ethical code and working with co-operation and coordination with their followers. Ethical political leadership put strong influence on the institutional and corporate sector and thus it is helpful in creating culture of harmony and co-operation.

As far as influence of political leader on corporate governance is concerned, the empowerment plays very important role to delegate the powers from top to low and increase the confidence of followers and workers. A good political leader transfer powers to their followers and in the same is applicable for the corporate leader to empower their employees and get the desired results. According to Gibson, Ivancevich Donnelly and Konopaske [19], empowerment is referred as granting powers to individuals and provides them permission to utilize their talents, skills and sources effectively. This is best way to get experience and make comprehensive decisions to get work done within their time frame. He also elaborated many examples which show the work that was previously done under the domain of management having less desirable results when compare to the work given to followers with complete liberty and free consent. In same manner the role of leader is not limited with his presence with followers but co-operation with his team member is crucial factor to consider by him. A good leader always tries to eliminate the inter-group conflicts, and always try to create the environment of co-operation and develop sense of responsibility within work groups.

\section{Conceptual framework}

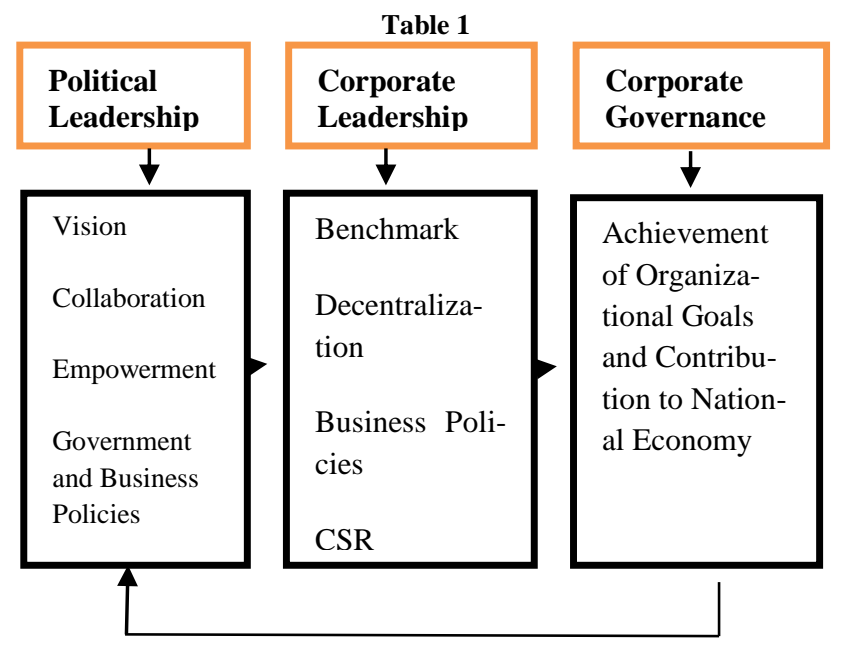

Successful leaders always specify vision as it shows the long run objectives to be achieved by the leader and followers in particular set up. Vision can show overall intellectual level of the leader and his approach towards achieving the goals and objectives with team-work spirit and sense of responsibility. To achieve the vision of any state or organization, the leader has to work in collaboration with his followers both in political and organizational setup. The vision specified by the political leader can provide a frame- 
work for the corporate leaders to follow and go through sustainable economic development.

A good leader always trains his followers as they can work even in the absence of their leader and achieve organizational goals. For the purpose, empowerment by leaders for followers is very crucial factor to recognize as it boosts up the confidence and ultimately increase the performance and quality of work at all. In organizational setup, leaders can copy this strategy and delegate their powers to their sub-ordinates for effective and better outcomes. Political leaders formulated government policies and provide essential frame work to build up their organization and business policies according to that direction. One of the important examples of political leadership is specification of policies regarding the Corporate Social Responsibilities (CSR) which is being followed by different organizations to prove them good corporate citizens. Organizational leadership always work in accordance to policies of political leadership as government has legitimate authority to monitor the policies of corporate sector and get effective feedback in this regard. In an ideal situation, the political leadership having competitive strategies is being followed by corporations and provides positive feedback to prove better corporate governance particularly and serve the community generally.

\section{Research design}

The purpose of this research is to identify the influence of political leadership on the corporate governance as good and bad political leaders may put positive and negative influence on the corporate sector. This study needs investigation of factors which may result in good as well as bad corporate governance arising from political leadership.

This research is quantitative in nature and it has been investigated that certain variables like government vision, collaboration with corporate sector, empowerment to business community and policies put strong influence on the corporate sector. The policy formulation and decision making ability of political leadership can provide a way for successful business strategies and also put negative impact on the corporate sector as well.

\subsection{Sources of information}

Keeping in view the requirement of the study both primary and secondary date collection methods have been used in this research study. Survey and interviews were conducted in order to know the influence of political leadership on corporate governance within Pakistan. For the purpose, some organizations from the corporate sector are selected to distribute the questionnaire and collect the response. Some information while interviewing to different people was collected through expert opinion as it was very necessary to have exact measurement of positive as well as negative influence.

\subsection{Questionnaire design}

This instrument includes close-ended questions representing the major variables like vison, collaboration, delegation of authority, government policies, benchmarking by corporate sector, feedback to government etc. The questionnaire is adopted from the previous literature review as it can show high accuracy and considered as valid questionnaire. The questionnaire scale is based on 5-point Likert scale interrelated from 1 to denote strongly Disagree and 5 indicates strongly Agree.

\subsection{Population and sample size}

The population frame of this study is limited to all employees who are working in corporate sector and government sector in Pakistan. Some major organizational from both government and private sectors are selected for collection of data. As most of the organizations were reluctant to provide exact number of their employees working in, therefore, sample of 100 respondents is selected as this is best way to select as least sample of 100 employees.

In order to justify the sample size rule of thumb laid by Roscoe [20] came in handy, who refers a sample size of larger than 30 and less than 500 as being the quite adequate size for most researchers. Therefore a sample size of 100 passengers has been selected for accurate and descriptive exploration.

\subsection{Sampling method and data analysis techniques}

This research includes convenience sampling method as population of different organization relating to private and government were scattered, hence, research has decided to select convenience sampling method. The research has tried his best to get ideas from that sample which have expert opinion and are considered in the front line of the management.

The data gathered was evaluated through descriptive tools like frequency tables, charts and diagrams. In addition to that, correlation and other statistical tools were used to go through effective analysis and see the overall relationship among the variables and impact of variables on each other.

\section{Data analysis and interpretation of data}

\subsection{Factor analysis}

In this research the statistical tool Factor analysis is used in order to reduce the numbers of variables which helps to identify the variance of factors. Principle Component Analysis method of Factor Analysis is used as it is most common used and default method in SPSS.

\subsubsection{KMO and Bartlett's test}

Table 2

\begin{tabular}{lll}
\hline Kaiser-Meyer-Olkin Measure of Sampling Adequacy. & .796 \\
\hline \multirow{3}{*}{ Bartlett's Test of Sphericity } & Approx. Chi-Square & 926.103 \\
& df & 190 \\
& Sig. & .000 \\
\hline
\end{tabular}

This test shows significant level as it is .000 which according to rule must be less than .05 . This analysis considered approximately Chi-square 926.103. The KMO and Bartlett's Test shows that, all the variables are correlated significantly different than zero; so this analysis is considered as highly significant. The sampling accuracy of this test stood as .796 which is good in practice.

In this research, 20 variables are used, as purpose of Factor Analysis is to reduce the variables into small number of components, total 5 factors are generated so for. As the matter of definition, the number of variables entered in this analysis must be equal to number of components shown in Total Variance Table Explained Table.

According to rule of thumb, the variables having Eigenvalue greater than 1.0 are retained and kept, as below of 1.0 Eigenvalue variables are not extracted in Total variance Explained Table. Extraction sum of square loading has loaded 5 components having 1.0 or above Eigenvalue. One way to know how good job this analysis has done by explaining the relationship between the variables as the \% of cumulative variance is 64.79 which is considered good in practice. To identify the variance percentage, the Eigenvalue of each factor is divided by number of variables like $7.192 / 20=0.3596$ which indicates 35.96 percentage of variance is explained by the component. 


\subsubsection{Scree plot}

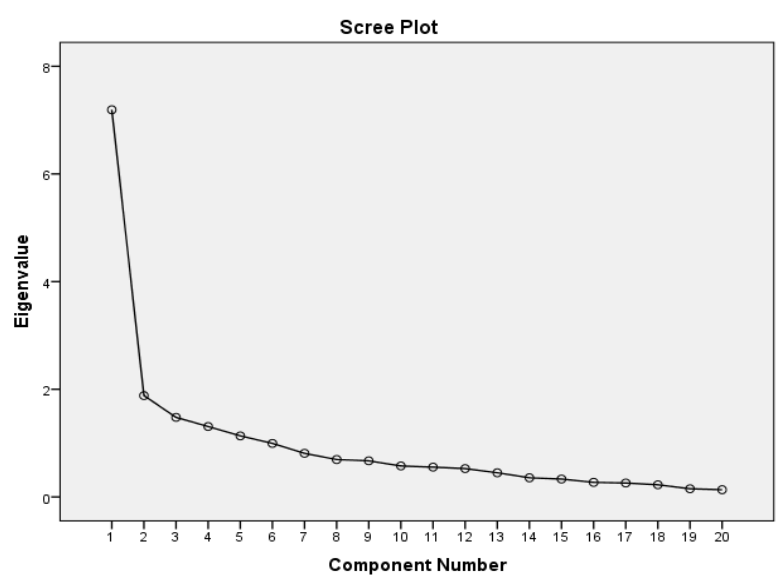

Chart. 1

Looking at the Scree Plot, it takes data (Eigenvalue) from Tota Variance Explained Table and exhibits the value of each component. This Scree plot visibly displays that there is big drop from component 1 to 2 while remaining 19 variables construct a flat line screening slow change.

\subsubsection{Component matrix}

The component matrix table shows good correlation among some variables as variable 15 loads .702 and variable 16 shows.744 correlations with component 1 . In the same manner, other variables exhibit like variable17 (.698) variable13 (.682), variable18 (.665), vaiable14 (622) percentage of correlation with component 1.

\subsubsection{Communalities}

Communalities table shows $\mathrm{R}^{2}$ of different variables as variable 1 accounts for .825 percentage of variance which is quite good in the practice. The other variables show like variable (.809), variable3 (.796), variable2 (.774), variable4 (.693), variable8 (.681), variable11 (.677), variable17 (671), variable16 (.654), variable15, (.653), variable12 (.637), variable7, (.607) and variable13 (602) percentage of variance which is also good in practice.

All the variables having less than 0.30 percentage or so, not contributing meaningfully, but since it is high in this case at .804 , it does contribute in naming it. This means "Leadership and Corporate Governance are essential for Organizational Development" contributing high variance with component. There is no variable having variance less than 0.30

Moving towards conclusion that 5 components are extracted or retrained, and by looking at different components, we name the list component as Leadership and Corporate Governance are essential for Organizational Development holding high with .825 percentages, which is quite excellent in practice. In this statistical tool factor, analysis showed good percentage of correlation among the variables with each other.

\subsection{Pearson correlation}

The statistical tool Pearson correlation (2- tailed) is used, which is showing some strong correlation among different variables, which are very important to consider.

Leadership and corporate governance is positively correlated with the variables government collaboration with corporate sector with correlation of .58, which emphasis on the strategy that government must work in collaborative way with corporate sector in order to improve the corporate governance and enhance its leadership qualities.

Additionally, variable leadership and corporate governance are also showing high correlation (.65) with variable collaboration that shows political leadership has to work closely and collaboratively with its stakeholders in order to get best results.

The correlation also shows good relationship exists between political leadership, corporate governance and political economy. This clearly indicates that political economy can go in upward direction if corporate sector is given chance in policy formulation and if there is strong and healthy relationship between political leadership, corporate governance and political economy.

The correlation measured between political leadership, and corporate sector was high as of .90 that absolutely shows that if government wants to increase its ability to produce more jobs and employment opportunities for people around, then it is very necessary to work collaboratively with corporate sector. In the same way the variable leadership and corporate governance are positively correlated with SMEs role in economic growth, that emphasis on better corporate governance. It also ensures and provides best ways to Small and Medium Enterprises to run their business effectively and help the political government in achieving economic targets.

\subsection{Instrument's reliability check}

In order to check the reliability of the instrument composed of the 20 attributes scale was adopted and filled by employees working in different government and public sector organizations. To check the instrument's reliability, Cronbach's Alpha test was run that turned out to be 0.757 for the 20 attributes.

Reliability index (cumulative)

Table 3: Reliability statistics

\begin{tabular}{ll}
\hline Cronbach's Alpha & N of Items \\
\hline 757 & 20 \\
\hline
\end{tabular}

\subsection{Response rate and gender category}

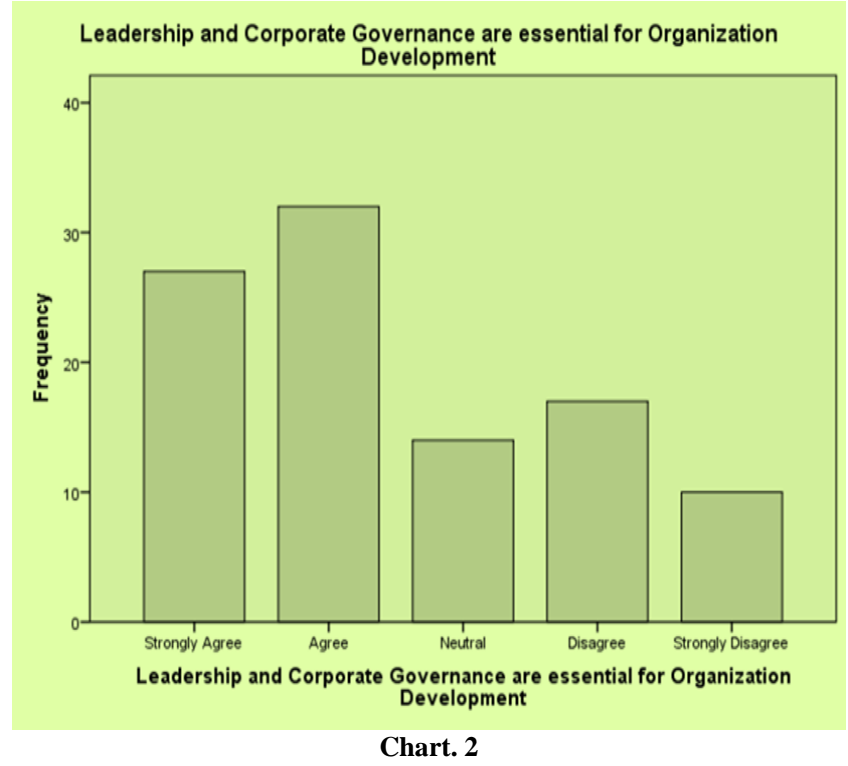

This chart clearly shows that majority of people are in favor that leader and corporate governance are important for organizational development, hence it proves that effective leadership influence the corporate governance. Approximately 59\% of respondents agreed, $14 \%$ remained neutral while $27 \%$ respondents were disagree with the statement. 


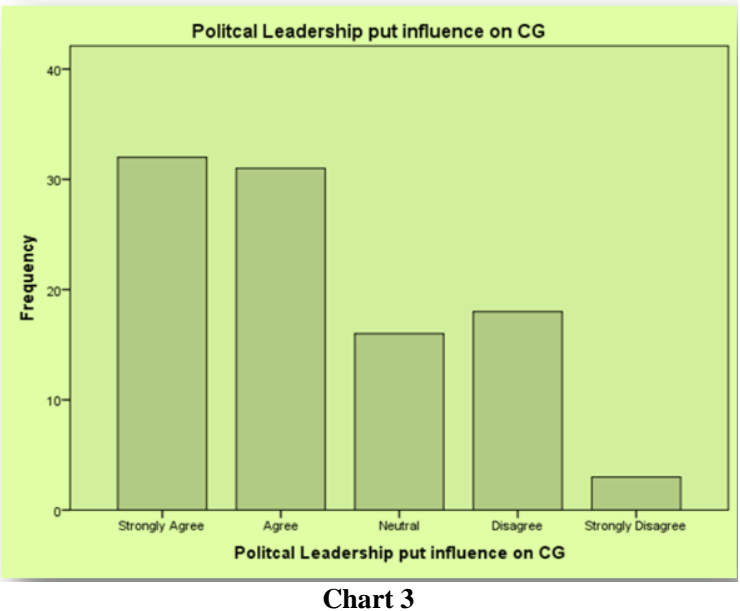

The important aspect of the data collection was the main question about influence of political leadership on corporate governance that clearly shows majority as of $63 \%$ of respondents were agree with the statement that political leadership influence the affairs of corporate sector, $16 \%$ of respondents remain neutral and $21 \%$ of respondents were disagree with the statement.

\section{Conclusions and recommendations}

Overall objective of this research is to analyze that political leadership has influence on the corporate governance as it is absolutely clears from the results that political leadership should plan effectively as its influence is not only on general public but also on corporate sector. Effective planning should lead to better political governance, which ultimately leads to better and productive corporate governance. Better corporate governance would also ensure the corporate social responsibilities (CSR) which encourages working for welfare of people within particular state. It clearly means that leadership, corporate governance and corporate social responsibilities are interrelated with each other. The influence of political leadership does not end here as result displays that it also put strong influence on small and medium enterprises, which are considered as backbone of any economy. During conversation with the employees of government and private sector organizations, they submitted the views about feedback to government is always sent by the corporate sector, but government must ensure the incorporation of all these suggestions and pay respect to the feedback provided by the decision maker of corporate sector. Respondents also favor the statement that corporate sector plays crucial role in eradication of the poverty among the masses and ensure sustainable economy, therefore, proper policy formulation and planning is very necessary by all stakeholders. Effective interaction and proper working methodology by political leadership as well as corporate sector can save the country from financial crisis, and run the state towards productivity and sustainable economic development and growth.

Here it is very important to discuss that respondents emphasized that getting near to better political and corporate system, it is very necessary that both political and corporate leaders must work with collaboration and complete harmony. Political leaders should provide complete freedom to corporate sector for making effective business policies and planning, and same goes to corporate sector to delegate the authorities to down level for better decision making and effective management. In addition to that, political leadership should specify effective business guidelines for the corporate sector as it provides clear framework and roadmap to business community and boosts up their confidence.

According to opinions, the successful political leaderships must have strong vision to specify and strong motivation to pursue the goals which leads towards economic prosperity and community development. Corporate sector and non-governmental organizations (NGOs) are working jointly with Governments on different projects like health, education and business policy and planning, which always ensure best results. The concept of collaborative work of public and private sector is most important discussion now days as a fruit for the joint work by both parties have always been got by the different stakeholders in the shape of better living standard and economic prosperity.

\section{Acknowledgement}

My first thanks are due to my respected Prof. Lv Tao and my colleagues Dr. Aftab Ahmed Shaikh, who provided every assistance and guidance during this research work. They provided their valuable suggestions during the preparation of this research paper.

I would also convey thanks to employees of Educational, Banking and governmental officials in public sector in Pakistan, who provided their great support and helped me to accomplish this task. Finally, many thanks go to my colleagues and friends who gave their input and improved the quality of this research work.

\section{References}

[1] Gill, R (2006) Theory and Practice of Leadership -London: sage publications

[2] Gardner W. L., Avolio B. J., Luthans F. et al. (2005). Can you see the real me? A self-based model of authentic leader and follower development. The Leadership Quarterly. https://doi.org/10.1016/j.leaqua.2005.03.003.

[3] Yukl, G. (2010). Leadership in Organizations, 7th ed. New Jersey: Prentice Hall.

[4] Boddy, D., \& Paton, D. (1998). Management: An Introduction. Great Britain: Prentice Hall Europe.

[5] Ebert, R. J., \& Griffin, R. W. (2009). Business Essentials, 7th Edition. New Jersey: Prentice Hall.

[6] Hsin-yi Cohen, (2016). Political leadership definition. Retrieved from leadership.expert.co.uk/political-leader-html.

[7] Mustafa, M.R., Ali et al. (2011). Study on risk management in rural and agricultural finance in the Near East and North Africa (NENA) Region, Food and Agriculture Organization of the United Nations Rome, Italy.

[8] Colley, J. Doyle J, Logan G, Stettinius, W. (2004), What is Corporate Governance? London: McGraw-Hill.

[9] Anuku, C.E.O \& Achienu, G.A (2001) Re-engineering corporate governance enterprise sustainable. Institute of Strategic Management, Nigeria (ISMN)

[10] Enabunene, S. (2005) Governance and Poverty Alleviation in Nigeria: Problems and Prospect National Conference, Faculty of Social Science, Ambrose Alli University Ekpoma July 4t - 6th.

[11] Ogundele, OJ.K, Alaka, N.S. an d Balogun, M.T (2005) Governance and Poverty, Poverty in Nigeria, National Conference, Faculty of Social Sciences, Ambrose Alli University, Ekpoma.

[12] Omozejie, P.I. (2005) Governance and Poverty Alleviation: The Nigerian Experience, Nation Conference; Faculty of Social Sciences, Ambrose Alli University, Ekpoma.

[13] Hofstede, G. (1980), Culture's Consequences: International Differences in Work-Related Values.

[14] Shailer, Greg. (2004). An Introduction to Corporate Governance in Australia, Pearson Education Australia, Sydney.

[15] Andreessen, E. J., \& Drenth, P.J.D. (1998). Leader ship: theories and models. In P. J. Drenth, A Handbook of Work and Organizational Psychology, 2nd edition (pp. 321 - 335). United Kingdom: Psychology Press.

[16] Kotter, J.P (1990) What Leaders Really Do, Harvard Business Review, May-June P. 103.

[17] Rost, J. C. (1993). Leadership for the twenty-first century: Praeger Publishers

[18] Rubin, R. S., Dierdorff, E. C., \& Brown, M. E. (2010). Do Ethica Leaders Get Ahead? Exploring Ethical Leadership and Promotability. Business Ethics Quarterly, 20 (2), 215-236. Sage, Beverly Hills, CA. Hofstede, G. and Hofstede, G.J. https://doi.org/10.5840/beq201020216.

[19] Gibson, J.L, Ivancevich, J.M., Donnelly, J.H., \& Konopaske, R. (2006). Organizations:

[20] Roscoe, J.T. (1975) Fundamental Research Statistics for the Behavioural Sciences, 2nd edition. New York: Holt Rinehart \& Winston. 